\title{
Technical Notes and Preliminary Experimental Tests on Scours Downstream of Bottom Sills in Asymmetrical Streams
}

\section{[ G. Ciaravino, L. Ciaravino ]}

\begin{abstract}
Hydrographic networks are becoming increasingly subject to unsteady flow regimes. These may be the result of a torrential habitat or because the flow is regulated by detention structures and can result in morphological instability. In such cases, the flow (which often divides into more than one branch) may meander along the river bed close to the bank, causing local scours to the bank and to any structures built along the river. A common technical practice is to employ bottom sills in order to stabilise mobile river beds and protect them from scour. This paper analyses some experimental tests conducted on bottom sills and points out that when the stream meanders unpredictably in the river bed or when the sill is at an angle to the stream, even though this flows in a single direction, the scour phenomenon is accentuated. As a result, assessments of scour in the proximity of river management works, carried out using the empirical formulas normally adopted in technical practice, may turn out to be totally insufficient.
\end{abstract}

Keywords—bottom sills, local scours, mobile river bed, experimental tests.

\section{Introduction}

In recent years, acknowledgment of the fact that climate change is affecting the operation of hydrographic networks has led academics, administrators and technical staff to reconsider the problems regarding the impact assessment and practical techniques of interventions to be carried out on stretches of water.

Successive seasons characterised by intense rainfall or severe drought are no longer an infrequent occurrence, even in geographical areas where a mild climate and the gradual passing of seasons has been the established norm.

Giulio Ciaravino

Professor, University of Naples Federico II, Italy

Luca Ciaravino

Professor MPI - PhD, Italy
For some environmental conditions, management of flow through regulation works such as detention basins and reservoirs, may be the most suitable solution to the problems and the damage caused by flooding or drought [1].

In a stretch of water with no artificial systems for regulating the natural flow $Q_{n}$ variable over time t, and indicating with $Q_{m v}$ the minimum vital flow (MVF), we can envisage two different cases [2]:

a) a natural flow regime $Q_{n}$ which, in the stretch of water in question, is always greater than or equal to $Q_{m v}$ : this regime, with $Q_{n} \geq Q_{m v}$, can be defined as fluvial;

b) a natural flow regime $Q_{n}$ which, in the stretch of water in question, falls below $\mathrm{Q}_{\mathrm{mv}}$ in non-negligible time intervals: this regime, with $Q_{n} \leq Q_{m v}$, can be defined as torrential.

In the second case, the section of river is clearly subject to natural events which, over a certain time, upset its morphological and environmental equilibrium.

If we consider only natural phenomena, the MVF might fall to a value of zero in torrential stretches of the water course during natural periods of drought due to a lack of rainfall or to local conditions when the river bed in question is highly permeable.

Where possible, as mentioned above, artificial regulation systems can be installed in torrential rivers so that part of the flow can be used to increase the natural flow value and ensure the MVF [3].

Furthermore, it is worth determining different MVF values for each month or season of the year in order to ensure the river always has a flow that conserves the variability of the natural flow regime on which the river's physical and biological equilibrium is based.

Therefore, whether they are subjected to an unsteady and random hydrological regime or the flow is regulated through detention works, hydrographic networks are increasingly subject to discontinuous hydraulic regimes with an unpredictable flow pattern.

The unsteady and variable nature of flows is also linked to the stream's energy content, which has a complex and, therefore, sometimes unpredictable effect on river morphology.

Moreover, we should not underestimate the fact that instability in the river flow is often dependent on the overall instability of the surrounding hillsides, which increases the 
chances of more dangerous instances of instability occurring.

It should also be observed that water courses are nearly always affected by man-made structures, which may result in local modifications to the hydrodynamic characteristics and often cause scour phenomena that may threaten the stability of the construction itself.

All the above phenomena are normally monitored and managed through appropriate interventions that must be carefully studied at a theoretical level and, if possible, verified by experimental analysis [4-24].

\section{Notes on usual design standards}

The study of works for consolidating and safeguarding the river environment naturally entails analysis of numerous parameters obtained from a variety of disciplines.

The problem outlined in the Introduction assumes a particular importance for torrential and/or discontinuous rivers where the river cross section, even when this is extremely wide, can be divided into two parts: one which collects the flow during droughts and under normal flow conditions, and the other which on more or less rare occasions transports the flows of floods, even when these are of exceptional entity.

In periods of drought, the flow has a reduced section which meanders from one bank to the other and often separates into several branches that change continually over time.

It may happen that as the stream meanders in the river bed, it comes close to the bank giving rise to erosion.

Generally speaking, these phenomena do not give reason for concern where the river is wider because they occur only briefly and in different locations.

However, in particular circumstances, such as bends in the river or where tributaries join the stream, the river bottom may become unstable for longer or shorter periods of time.

In this case, scours at the base of the banks may, over time, cause the ground above to slide into the river.

Furthermore, the meandering stream accentuates erosion phenomena in the proximity of structures built along the river, underlining that the presence of any obstacle or variation in section that gives rise to eddy currents initiates a phase in which rapid erosion takes place.

A valid hydraulic arrangement must therefore aim to:

a) protect the banks where structures have been built whenever there is a risk of erosion due to eddies, either because of floods or because of shifts in the water course during normal flow conditions,;

b) establish river bottom depths that stabilise the hydraulic processes linked to scour phenomena.

In other words, after identifying the stretches of water in which river instability conditions may arise (for geological, geotechnical and hydrodynamic reasons), it is necessary to locate the sites in which erosion takes place because of obstructions or constrictions in the stream due to structures that have been built along the river.
In such places, bottom sills are widely used in technical practice to ensure protection from erosion and to stabilise mobile river beds.

These are transverse structures, made of concrete and/or natural stone, with a relatively small width and reaching a few metres below the river bed, which typically make it possible to consolidate water courses at a relatively low cost.

In actual fact, while it is widely acknowledged that a careful use of bottom sills enables the overall stabilisation of stretches of water, it is equally well known that bottom sills do not prevent local scours which generally occur downstream from the sills, and this erosion can cause the structure to collapse and, in the case of bottom sills, can render such interventions ineffectual.

The definition of scour around isolated structures in a stream flow, such as bridge piles located in an erodible river bed, is a problem of considerable technical importance as the erosion can assume values such as to compromise the stability of the structure in a very short time frame.

Scours are known to be influenced by the shape and size of the pile and are significantly affected by their layout with respect to the stream flow.

In other words, the shape, size and layout of the pile constitutes essential information for an assessment both of the erosion in the river bed and of the hydrodynamic effects of the stream on the structure.

As a result, research to find geometric configurations that successfully contain the occurrence of scours is an issue of major importance in the design field.

In technical practice, designers often prefer the circular pile, which not only has a favourable value for the shape coefficient but also maintains this value for any variation in stream direction and is therefore, particularly suitable for torrential regimes.

Bottom sills are also often used in the case of isolated bodies to protect the structure from instability due to scour

However, in neither case are there standards or truly accurate indications for assessing scours.

Consequently, the design and/or stability assessment of such works is often conducted according to empirical practices or experimental assessments and/or theoretical models that normally refer to plane motion studies and thus the flow is uniformly distributed along the transverse section.

\section{Preliminary experimental tests}

In the context of the research programmes mentioned in the Introduction [23, 24], scour tests were carried out around bottom sills and river piles.

In the initial experimental tests on local scours downstream of bottom sills, two different layouts were compared (Fig. 1): a bottom sill positioned orthogonally to the channel axis and a bottom sill set at $45^{\circ}$ to the channel axis.

Three tests with different flow values were carried out for each layout.

In particular, for the bottom sill orthogonal to the axis, the flows were: $0.0110 ; 0.0210 ; 0.0426 \mathrm{~m}^{3} / \mathrm{s}$.

Whereas, for the $45^{\circ}$ inclined sill, the flows were: $0.0100 ; 0.0220 ; 0.0426 \mathrm{~m}^{3} / \mathrm{s}$. 
Proc. of the Sixth International Conference on Advances in Civil, Structural and Environmental Engineering - ACSEE 2017. Copyright $@$ Institute of Research Engineers and Doctors. All rights reserved.

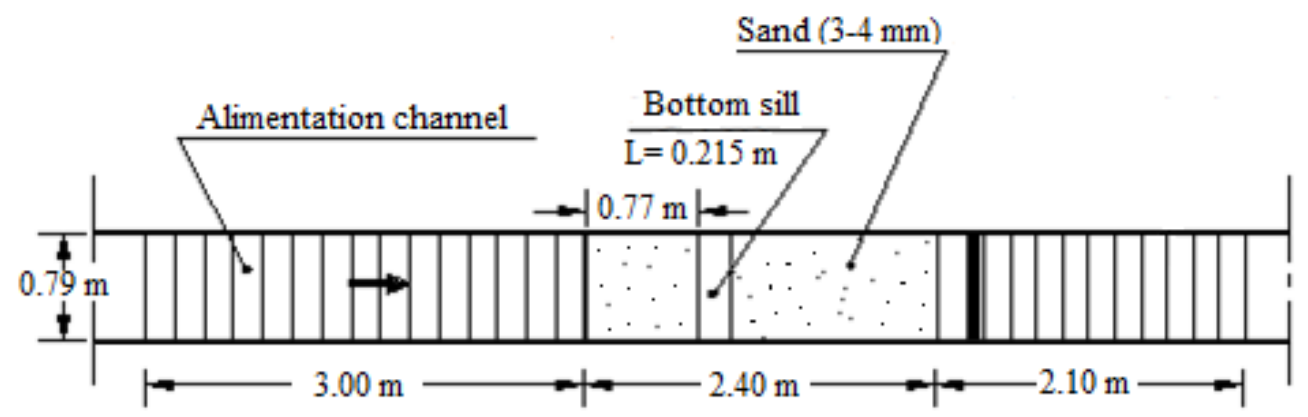

Plan view

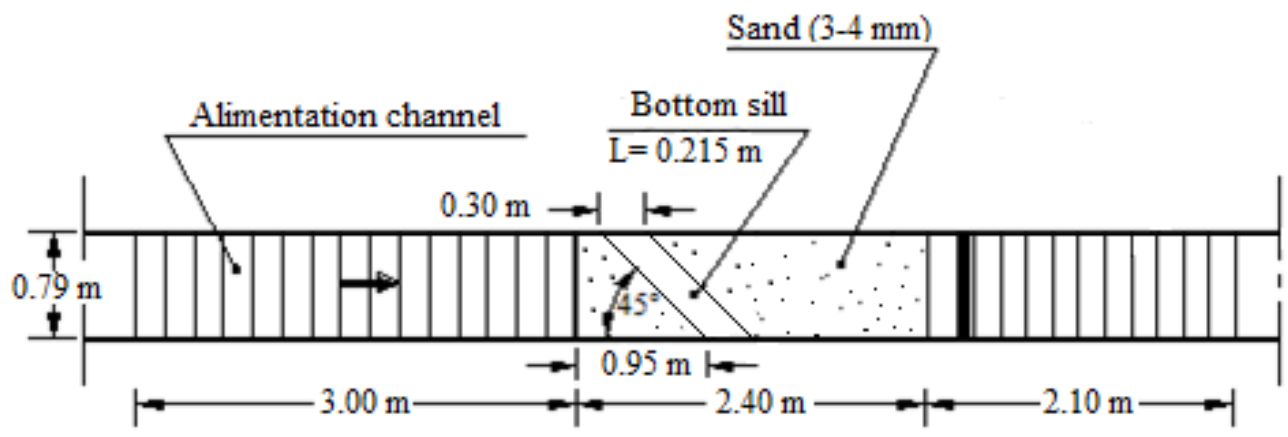

Plan view

Figure 1. Experimental installation with bottom sills used.
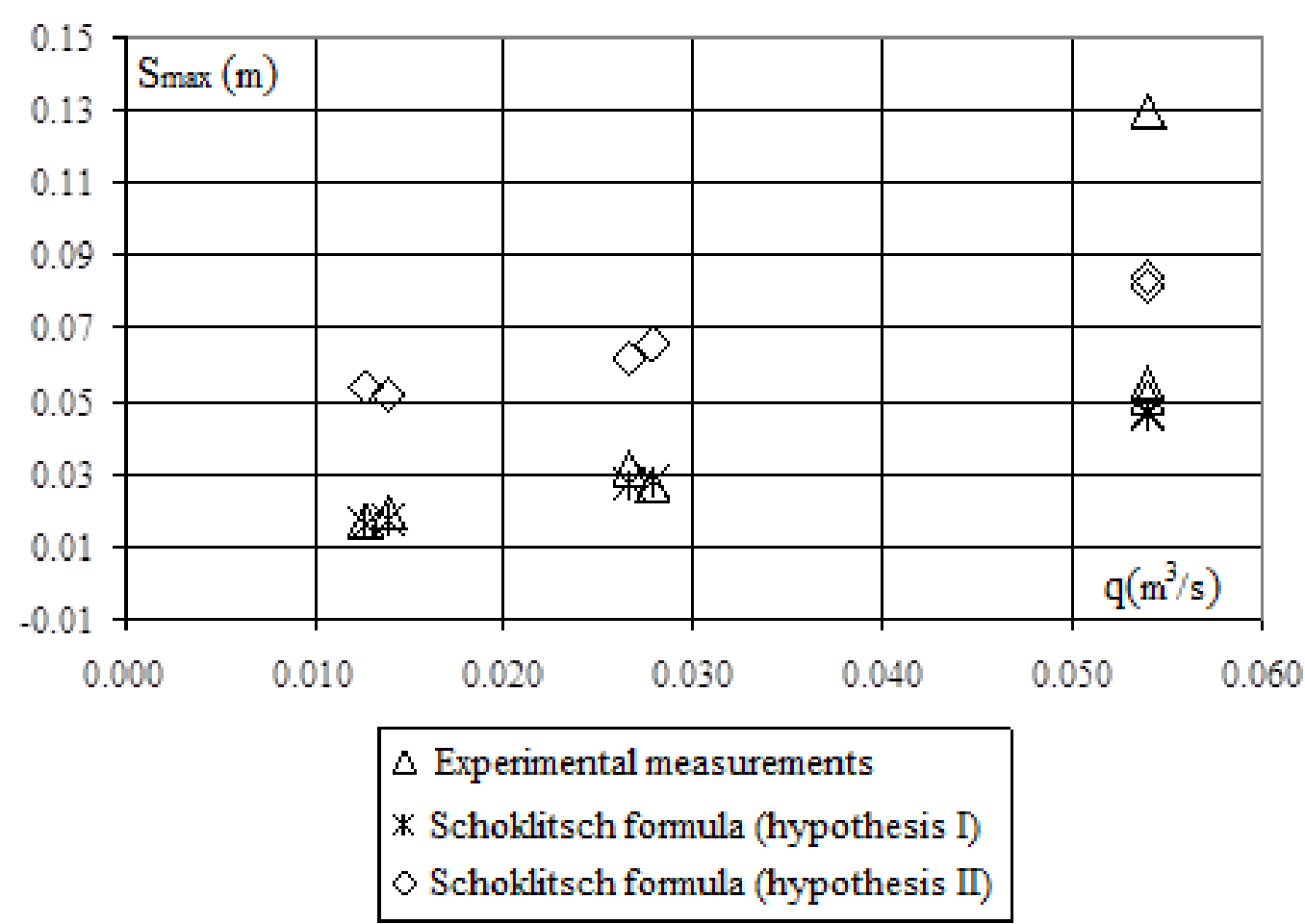

Figure 2. Comparison between experimental measurements and values calculated using the Schoklitsch formula. 
Each of the experimental tests lasted 1 hour 30 minutes, during which time the measurements for the scour depth and the corresponding free surface level were taken.

These measurements were taken starting from the moment at which a practically negligible solid transport was observed in the downstream section.

During the tests the free surface (and consequently also the erodible river bed) was characterised by conditions of non-stationary motion for the first part of the tests conducted.

In particular, for conditions at the lower flow rates in both layouts a series of waves formed whose length increased over time until stabilising when solid transport became negligible.

And in both layouts, at the highest flow rate this phenomenon evolved more rapidly with waves of greater height and amplitude.

For the bottom sill orthogonal to the axis, the observed wave initiates in parallel to the sill for the first larger wave and with the greatest erosion on the river bottom.

Thereafter, the waves remain parallel to the position of the bottom sill.

For a bottom sill set at a $45^{\circ}$ angle, the wave motion again initiates in parallel to the sill at the first larger wave but, thereafter, the wave fronts tend to rotate until they are orthogonal to the channel axis (thus leaving the oblique alignment of the sill).

However, this phenomenon is not symmetrical across the whole width of the channel, thus dividing the channel into two areas:

a first area (corresponding to the part of the stream which leaves the sill first) where the waves rotate until they are orthogonal to the channel axis and remain visible;

a second area (corresponding to the part of the stream which leaves the sill later) where the wave phenomenon is much less marked and barely visible.

This phenomenon diminishes for larger flow rates.

In order to determine maximum scour $S_{\max }$, a comparison between the two layouts adopted points out the role of the different turbulent action, also highlighted by the above described asymmetrical pattern of surface waves, which was observed when the experimental tests were being developed.

A transverse movement of the material making up the mobile river bed is created and seems to produce, albeit to a small degree, less scouring in the axis and transfers the greatest scouring to the lateral area corresponding to the part of the stream that first leaves the bottom sill (where the waves rotate until they are orthogonal to the channel axis), while on the opposite side conspicuous depositing of scoured material can be observed.

In order to carry out a homogeneous comparison, the maximum scours $S_{\max }$ measured in the experimental channel axis were compared with the values that can be calculated in a symmetrical stream using the well-known Schoklitsch formula [25]:

$$
S_{\max }=0.378 \cdot H^{0.5} \cdot q^{0.35}+2.15 \cdot \delta
$$

where $H$ is the total specific head, $q$ is the specific flow and $\delta$ is the difference in height between the bottom sill and the bottom of the erodible channel downstream from the scour phenomena.

In an initial simplified hypothesis ( $I$ ), if we make $\delta=0$ we obtain the results reported with an asterisk in Fig. 2, while, in a second hypothesis ( II ) if we make $\delta$ equal to the difference in height between the test sill and the sill placed at the end of the erodible section, we obtain those indicated with a rhombus in Fig. 2.

A comparison with the experimental values (in terms of specific flow rate) reported with a triangle in Fig. 2, shows excellent agreement between the experimental points measured in the axis and those calculated using the Schoklitsch formula in the first hypothesis above.

However, the same comparison reveals a considerable underestimation of the maximum scour value $S_{\max }$ calculated using the Schoklitsch formula (in both hypotheses) with the one measured experimentally to the side of the oblique bottom sill and maximum flow rate and attributable to the asymmetry.

These preliminary tests - which must be enhanced by varying the sill width and the angle with respect to the channel axis - nevertheless give a highly significant qualitative indication of scour phenomena.

In other words, either when the stream may meander unpredictably in the river bed or when the stream follows a definite direction but the bottom sill is oblique to it, the experimental results highlight and suggest that an asymmetric stream flow over the bottom sill (even with a greater flow rate) accentuates the erosive phenomenon .

As a result, scouring is much greater than can be estimated through the empirical formulations normally used for this purpose in technical practice which, as mentioned above, is normally based on plane motion hypotheses and a uniform flow distribution along the transverse section.

\section{Discussed hypothesis}

The experimentally observed phenomenon can be explained through simplified stream hypothesis in which a constant head value is hypothesised for all elements belonging to the same vertical in which, moreover, velocity can vary from point to point.

In actual fact, the above phenomenon is accompanied by an asymmetric transverse inclination of the free surface.

Therefore, if we consider a single generic water column with a unitary base and a head $h$ equal to the water depth, we can hypothesise an equilibrium when the action component $T$ due to a transverse slope, essentially equal to:

$$
T=\gamma \cdot h \cdot I_{t}
$$

where $\gamma$ is the specific weight of the water and $I_{t}$ is the transverse inclination of the free surface, equals the force $F$ due to the variation in velocity. 
However, as velocity is variable along the vertical, it may turn out that $T$ is different from $F$ both at the free surface and close to the bottom.

In this case, as has been observed experimentally, a stream may form on the free surface in the direction of the side where it first leaves the bottom sill (thus justifying the rotation of the above described wave phenomena), while near the bottom a transverse current can always be generated and its velocity is combined with that of the stream affecting the rest of the bottom sill.

The described motion field can certainly justify both the greater erosion observed during the experiments in the area where the current first leaves the bottom sill, and the materials deposited on the opposite side.

\section{v. Conclusions}

The preliminary tests carried out in conditions of asymmetrical stream, although limited in scope, nevertheless give a highly significant qualitative indication of the scour phenomenon downstream of bottom sills.

In the light of the analysis performed - in particular in the case of a river in an unsteady flow regime where asymmetry conditions can very frequently arise - we can draw the conclusion that in stabilisation operations (both local and of a more longitudinal nature) prudence must be adopted in design criteria.

These criteria can be based on the adoption of bottom sills with pile foundations in stabilisation operations and deformable longitudinal bank protection (naturalised rocks, gabions, etc.) whose performance seems to meet the need.

In fact the bottom sill with pile foundation has a structural layout that makes it possible to restrict its height and width, to maintain its static function even when structural continuity is interrupted and, above all, to maintain its stability even in the event of major local scours which might arise if the stream follows an asymmetric pattern.

It also appears to be worth including a centre-to-centre between the foundation piles in order to allow a sufficient and acceptable possibility for stream flow below the river bed.

It is also worth stressing that in order to avoid and/or mitigate the above highlighted problems related to asymmetry and due to the possibility of the stream meandering, it appears a worthwhile practice (and not only in economic terms) to follow the criterion of looking for river stretches with narrower transverse sections in which to establish monitoring sections (of significant length and fitted with bank defences and bottom sills) that have a mainly straight and geometric flow pattern.

It is also necessary to avoid siting isolated structures and bottom sills in bends, inside which low-lying, longitudinal bank defences should be preferred.

It is useful to safeguard the outer bank in bends withy low-lying defences followed by a bottom sill after the stretch of river has become essentially straight.

\section{References}

[1] G. Ciaravino, "Role of outlet works in management and control of floods. Dams and Reservoirs", Societies and Environmental in the 21st Century. Berga et Al. (eds), Taylor \& Francis Group, London, pp. 223-230, 2006.
[2] P. Manciola, P. Martini, L. Umbertini, "Significato del Deflusso Minimo Vitale e sua determinazione per un corso d'acqua dell'Italia centrale", Idrotecnica, n.2, pp. 79-91, 1994, (in Italian).

[3] G. Ciaravino, L. Ciaravino, "Captazione potabile e DMV in un tronco fluviale in regime naturale torrentizio", Acqua e Città, Convegno Nazionale di Idraulica Urbana, Architettura del Paesaggio, Eds AIAPP, Ottobre-Dicembre, 2007, (in Italian)..

[4] G. Lacey, "A general theory of flow in alluvium", Jr. Institute Civ. Eng., vol. 27, 1946.

[5] M. Viparelli, "Erosioni a valle di una traversa di sbarramento", Publication No.47, Università di Napoli, Istituto di Idraulica e Costruzioni Idrauliche, 1947 (in Italian).

[6] L. Ciaravino, "Observations concerning erosion in model of a mobile river bed", Proceedings River Flow 2004, Naples, Italy, Vol. 1, pp. 647-656, 2004.

[7] Adduce, C., Sciortino, G., Morganti, M. "Numerical and experimental investigation of local scour downstream of a sill", Proc. Second Int. Con. on Fluvial Hydraulics River Flow, Napoli, 2004.

[8] G. Ciaravino, L. Ciaravino, "Verification on physical model of the erosion downstream of an asymmetrical flow", In Institut fur Wasserbau und Technische Hydromechanik. Flow Simulation in Hydraulic Engineering, Dresden: Selbstverlag der Technischen Universitat Dresden (Germany), Vol. Mitteilungen Heft 32, pp. 501$508,2006$.

[9] M. R. Cartens, "Similarity laws for localized scour", Proc. ASCE, HY 3, 1966.

[10] A. Adami, "Uno schema di calcolo per la determinazione della escavazione a valle di traverse", L'Energia Elettrica, n.12, 1971 (in Italian).

[11] J. Farhoudi, K.V.H. Smith, "Time scale for scour downstream of hydraulic jump", Journal of Hydraulic Engineering, ASCE, Vol.108, No.10, pp. 1147-1162, 1982

[12] J. Farhoudi, K.V.H. Smith, "Local scour profiles downstream of hydraulic jump", Journal of Hydraulic Research, IAHR, Vol.23, No.4, pp. 343-358, 1985.

[13] F. Nola, G. Rasulo, "Escavazioni a valle di dissipatori a risalto", Idrotecnica, n.2 Marzo-aprile, pp.63-74, 1989 (in Italian)

[14] N. Rajaratnam,R.K. Macdougall, "Erosion by plane wall jets with minimum tailwater", Journal of Hidr.Eng., ASCE, Vol.109, pp.10611064, 1983

[15] H.N. Breusers, A.J. Raudkivi, "Scouring", Hydraulic Structures Design Manual IAHR, A.A. Balkema, Rotterdam, 1991.

[16] G.J.C.M. Hoffmans, H.J. Verheij, "Scour Manual", Rotterdam: Balkema, 1997.

[17] W.H. Graf,M.S. Altinakar, "Fluvial Hidraulics", J.Wiley and Sons, London, G.B., 1998.

[18] O.A. Karim,K.H.M. Ali, "Prediction of flow Patterns in local scour holes caused by turbulent water jets", Journal of Hidr. Research, Vol.38, pp. 279-287, 2000.

[19] G. Oliveto, W. H. Hager, "Temporal evolution of clear-water pier and abutment scour", Journal of Hydraulic Engineering, ASCE, Vol.128, No.9, 811-820, 2002

[20] W.H. Hager, G. Oliveto, "Shields' entrainment criterion in bridge hydraulics", Journal of Hydraulic Engineering, ASCE, Vol.128, No.5, pp. 538-542, 2002.

[21] B. Dargahi, "Scour development downstream of a spillway", Journal of Hydraulic Research, IAHR, Vol.41, No.4, pp.417-426,2003.

[22] G. Oliveto, V. Comuniello, B. Onorati, "Local scour downstream of stilling basins", In Dohmen-Janssen \& Hulscher (eds), River, Coastal and Estuarine Morphodynamics: RCEM 2007, Vol.2, pp. 1227-1231, 2007.

[23] L.Ciaravino, G. Ciaravino, "Preliminary experimental tests of local erosion at river piers with a particular shape", Eds. C. A. Brebbia. River Basin Management V, WIT Transactions on Ecology and the Environment, Vol. 124, pp.247-256, 2009.

[24] L. Ciaravino, "Primi risultati sperimentali di erosioni localizzate a valle di sagome di fondo in correnti asimmetriche", XXX Conv. di Idraulica e Costruzioni Idrauliche, Roma, 2006 (in Italian).

[25] A. Schoklitsch, "Stanraum verlandung und Kolkbwehr", Sprinter, Wienna, 1935. 